\title{
New cyclization reactions in organic syntheses*
}

\author{
Iwao Ojima \\ Department of Chemistry, State University of New York at Stony Brook, Stony \\ Brook, NY 11794-3400, USA
}

\begin{abstract}
Recent development in the transition metal-catalyzed cyclization reactions for organic syntheses in the author's laboratories is summarized, which includes (i) novel silylcarbocyclizations ( $\mathrm{SiCaCs}$ ) and carbonylative carbotricyclizations, (ii) intramolecular silylformylations and desymmerization of siloxydiynes by sequential double silylformylation, (iii) efficient total synthesis of (+)-prosopinine, (iv) enantioselective desymmetrization of aminodienes, and (iv) new and efficient routes to 1-azabicyclo[x.y.0]alkane amino acids. All these processes are catalyzed by $\mathrm{Rh}$ or $\mathrm{Rh}-\mathrm{Co}$ complexes, and useful for rapid and efficient construction of a variety of heterocyclic and carbocyclic compounds. Mechanisms of these new carbocyclization and cyclohydrocarbonylation reactions are also discussed.
\end{abstract}

It has been the central focus in modern organic synthesis to develop highly efficient catalytic processes for the syntheses of natural and unnatural compounds of medicinal interest or intermediates useful for functional materials. One of the most attractive approaches to such aims is to apply transition metal-catalyzed cyclization reactions for the transformations of simple starting materials into monocyclic, bicyclic, and polycyclic scaffolds that can be further elaborated into specific targets.

This account describes new and useful cyclization processes based on silylcarbocyclization ( $\mathrm{SiCaC})$, silylformylation, and cyclohydrocarbonylation reactions, which have recently been developed in these laboratories and will find many applications in organic syntheses.

\section{SILYLCARBOCYCLIZATIONS (SiCaCs)}

The first silylcarbocyclization was discovered serendipitously during our detailed product analysis of the silylformylation of 1-hexyne catalyzed by $\mathrm{Rh}$ and $\mathrm{Rh}-\mathrm{Co}$ carbonyl clusters, which gave dibutylcyclopentenone by incorporating two molecules of 1-hexyne, one molecule of hydrosilane, and one molecule of CO. Following up this discovery, we have investigated the intramolecular version of this reaction using a variety of 1,6-enynes, which led to the discovery of novel silylcarbocyclization ( $\mathrm{SiCaC})$ reaction (eq. 1) [1-3]. The $\mathrm{SiCaC}$ reaction of 1,6-enynes is catalyzed by $\mathrm{Rh}_{4}(\mathrm{CO})_{12}$ and $\mathrm{Rh}_{2} \mathrm{Co}_{2}(\mathrm{CO})_{12}$,

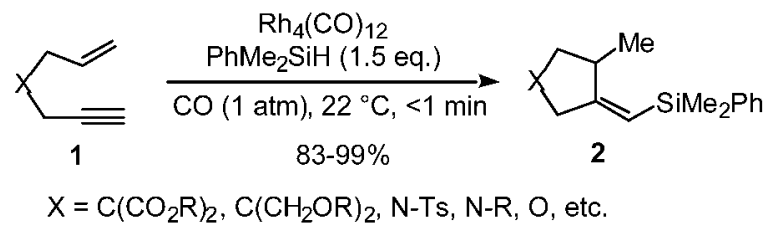

*Lecture presented at the $11^{\text {th }}$ IUPAC International Symposium on Organometallic Chemistry Directed Towards Organic Synthesis (OMCOS-11), Taipei, Taiwan, 22-26 July 2001. Other presentations are presented in this issue, pp. 1-186. 
which enable the reaction to proceed at ambient temperature and completes mostly within a minute. Other Rh catalysts such as $\mathrm{Rh}(\mathrm{acac})(\mathrm{CO})_{2}$ are also effective for this reaction, but require $65-70{ }^{\circ} \mathrm{C}$ to promote the reaction efficiently. Although $\mathrm{CO}$ is not incorporated into the $\mathrm{SiCaC}$ products, the cluster catalysts require $\mathrm{CO}$ atmosphere to stabilize the active catalyst species [1-3].

When the $\mathrm{SiCaC}$ reaction of an enyne with a hydrosilane is carried out under higher pressure of $\mathrm{CO}(20 \mathrm{~atm})$ at dilute conditions and/or in the presence of a phosphite ligand (5 equiv/Rh), carbonylative $\mathrm{SiCaC}$ reaction $(\mathrm{CO}-\mathrm{SiCaC})$ takes place virtually exclusively (eq. 2) [3].

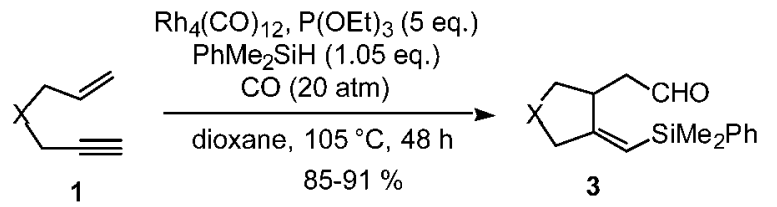

The $\mathrm{SiCaC}$ reaction is applicable to 5-alkynals, which afford 2-exo-silylmethylenecyclopentanols in high yields [4]. The $\mathrm{SiCaC}$ reactions that accompany subsequent hydrosilylation ( $\mathrm{SiCaC}-\mathrm{HS}$ ) have also been studied [2]. We have also discovered and developed novel Rh-catalyzed silylcarbobicyclization $(\mathrm{SiCaB})$ of 1,6-diynes, which gives the corresponding 2-silylbicyclo[3.3.0] oct- $\Delta^{1,5}$-en-3-ones [5] or 2-silylbicyclo[3.3.0]octa-1,5-dien-3-ones [6], depending on the specific reaction conditions, in excellent yields.

\section{CASCADE SILYLCARBOCYCLIZATIONS}

Mechanistic analysis of $\mathrm{SiCaC}$ reactions indicates that cascade silylcarbocyclization reactions are possible through successive intramolecular carbocyclizations as long as competing reductive elimination is slower than carbometalation. For example, the reaction of dodec-6-ene-1,11-diyne 4 with $\mathrm{PhMe}_{2} \mathrm{SiH}$ catalyzed by $\mathrm{Rh}(\mathrm{acac})(\mathrm{CO})_{2}$ at $50{ }^{\circ} \mathrm{C}$ and atmospheric pressure of $\mathrm{CO}$ gives bis(exo-methylenecyclopentyl) 5 (eq. 3) [7]. The reaction is stereospecific, i.e., (6E)- and (6Z)-dodec-6-ene-1,11-diynes, (E)-4 and $(Z)-\mathbf{4}$, afford $\left(R^{*}, R^{*}\right)-\mathbf{5}$ and $\left(S^{*}, R^{*}\right)-\mathbf{5}$, respectively.

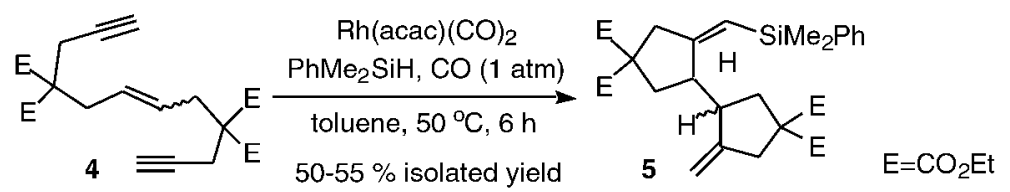

Although there was a possibility that the third carbocyclization takes place to form a tricyclic product, this process did not occur. This was attributed to the rotational freedom of the $\mathrm{C}-\mathrm{C}$ bond connecting two cyclopentyl moieties in a key intermediate, i.e., the carbocyclization process cannot compete with reductive elimination.

It was anticipated, therefore, that restricting the rotational freedom of the $\mathrm{C}-\mathrm{C}$ bond connecting two cyclopentyl moieties by incorporating a double bond would make the third carbocyclization possible [8]. Indeed, the reaction of dodeca-1,6,11-triyne $6\left[\mathrm{X}=\mathrm{C}\left(\mathrm{CO}_{2} \mathrm{Et}\right)_{2}\right]$ under the standard $\mathrm{SiCaC}$ conditions using $\mathrm{Rh}(\mathrm{acac})(\mathrm{CO})_{2}$ as the catalyst and $\mathrm{PhMe}_{2} \mathrm{SiH}$ as the hydrosilane at $70{ }^{\circ} \mathrm{C}$ gave a $2: 2: 1 \mathrm{mix}-$ ture of 7, 8, and 9 in $94 \%$ total yield, achieving the first silylcarbotricyclization ( $\mathrm{SiCaT}$ ) via three consecutive carbocyclizations (Scheme 1) [8]. Under optimized conditions using $\mathrm{Rh}_{4}(\mathrm{CO})_{12}$ as the catalyst and 2 equiv of hydrosilane to 6 at $22{ }^{\circ} \mathrm{C}$, fused tricyclic silylbenzene 7 was obtained in excellent yield with $84-93 \%$ selectivity. Several $\mathrm{Rh}$ complexes were found to be effective in the SiCaT reaction, which are $\mathrm{Rh}(\mathrm{acac})(\mathrm{CO})_{2},\left[\mathrm{Rh}(\mathrm{NBD})_{2} \mathrm{Cl}\right]_{2},\left[\mathrm{Rh}(\mathrm{COD})_{2} \mathrm{Cl}_{2}, \mathrm{Rh}_{4}(\mathrm{CO})_{12}\right.$, and $\mathrm{Rh}_{2} \mathrm{Co}_{2}(\mathrm{CO})_{12}$. A variety of hydrosilanes such as $\mathrm{PhMe}_{2} \mathrm{SiH}, \mathrm{Ph}_{2} \mathrm{MeSiH}, \mathrm{Ph}_{3} \mathrm{SiH}, \mathrm{Et}_{3} \mathrm{SiH}, t$ - $\mathrm{BuMe}_{2} \mathrm{SiH}$, (EtO) ${ }_{3} \mathrm{SiH}$, and $(\mathrm{EtO})_{2} \mathrm{MeSiH}$, can be used in this reaction. Various 1,6,11-triynes including those with oxygen and/or 
nitrogen atoms in the backbone are proven to be good substrates for this process. Fused tricyclic benzene $\mathbf{8}$ was formed exclusively using exactly stoichiometric amount of $\mathrm{PhMe}_{2} \mathrm{SiH}$.

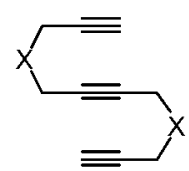

6

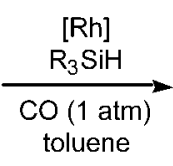

$\mathrm{X}=\mathrm{C}\left(\mathrm{CO} \mathrm{Ct}_{2} \mathrm{C}_{2}\left(\mathrm{CH}_{2} \mathrm{OM}\right.\right.$

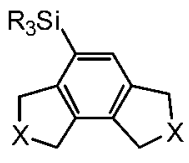

7

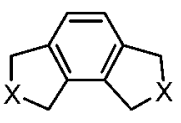

8

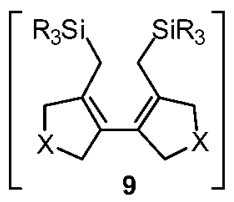

9

Scheme 1

A proposed mechanism for the SiCaT reaction is illustrated in Scheme 2, which includes initial insertion of an alkyne moiety of $\mathbf{6}$ into the $\mathrm{Si}-[\mathrm{Rh}]$ bond of the active catalyst species followed by three consecutive carbometallations [8]. Deuterium labeling experiment confirmed the cascade process and eliminated the involvement of any common metallacycle in the catalytic cycle. The formation of the non-silyl product $\mathbf{8}$ is explained by the occurrence of the Ojima-Crabtree-type rearrangement [9] of intermediate $\mathbf{I}$ and $\beta$-silyl elimination of $\mathrm{Si}-[\mathrm{M}]$ species from intermediate $\mathbf{V}$ [8].

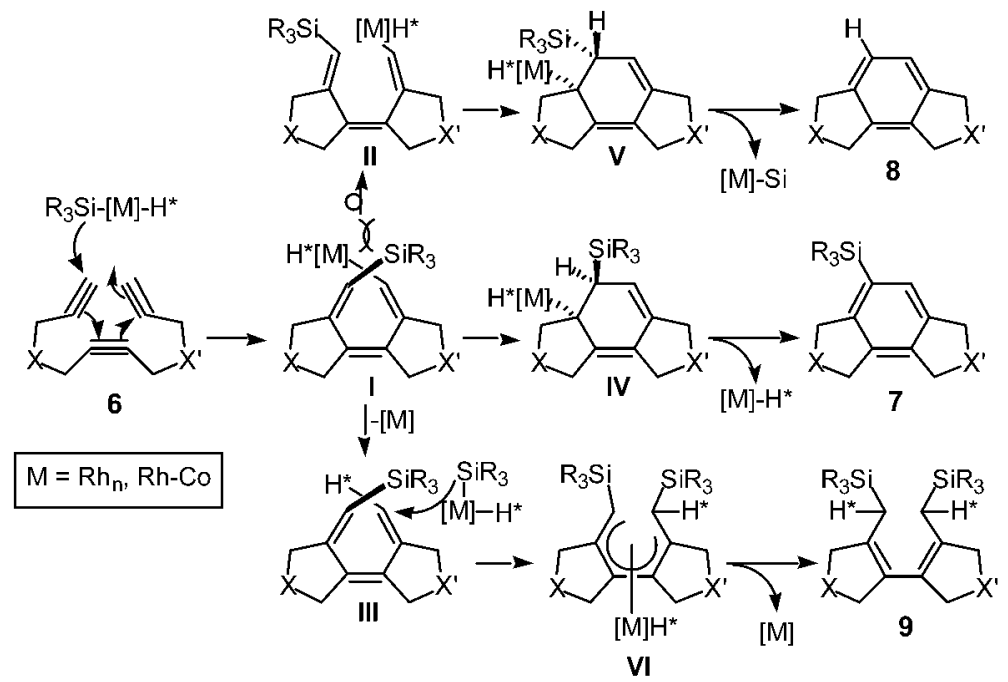

Scheme 2

The SiCaT reaction is applicable to the construction of 6-6-5 and 6-6-6 fused tricyclic skeletons such as 11 and 12 (eq. 4) [8]. Since the formation of 6-membered ring other than benzene ring by catalytic carbocyclization is demanding in general, the ability to construct such ring systems is synthetically significant and advantageous. Also, the 6-6-5 and 6-6-6 fused ring systems find plenty of applications to the syntheses of medicinally active compounds.

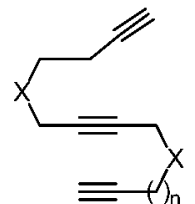

10 $\mathrm{X}=\mathrm{C}\left(\mathrm{CO}_{2} \mathrm{Et}\right)_{2}$

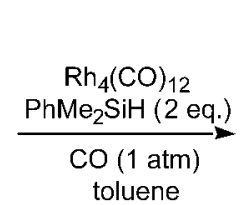

b: $n=2,40^{\circ} \mathrm{C}, 24 \mathrm{~h}, 69 \%, 11 \mathrm{~b} / 12 \mathrm{~b}=48 / 52$

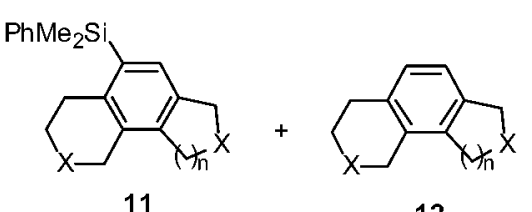

12 


\section{CARBONYLATIVE CARBOTRICYCLIZATION OF ENEDIYNES}

As an extension of the $\mathrm{SiCaT}$ reaction, the reaction of dedec-11-ene-1,6-diyne 13a $\left[\mathrm{X}=\mathrm{C}\left(\mathrm{CO}_{2} \mathrm{Et}_{2}\right)_{2}\right]$ with $\mathrm{PhMe}_{2} \mathrm{SiH}$ catalyzed by $\mathrm{Rh}(\mathrm{acac})(\mathrm{CO})_{2}$ was carried out at $70^{\circ} \mathrm{C}$ and $\mathrm{CO}$ atmosphere with expectation of obtaining 5-6-5 tricyclic product. However, the reaction gave cyclopenta[e]azulene 14a and bis(cyclopentylidene) 15a as major products and aldehyde 16a as minor product in $70 \%$ overall yield (14a:15a:16a = 36:43:21) (Scheme 3) [10]. This marks the serendipitous discovery of the novel and synthetically very attractive carbonylative carbotricyclization process incorporating $\mathrm{CO}$, forming 5-7-5 fused ring system.

Scheme 3
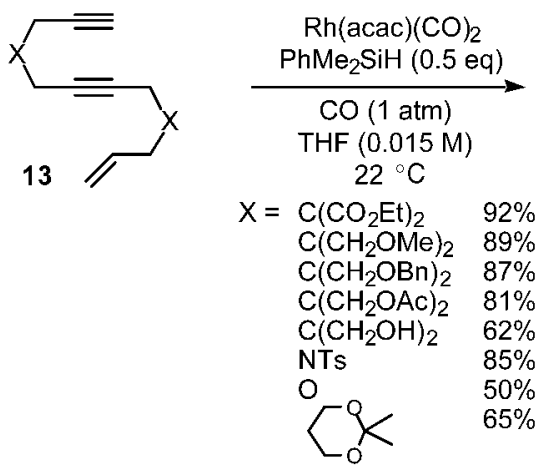<smiles>[X]CC1=CC(=O)CC2CC[Y]CC12</smiles>

14

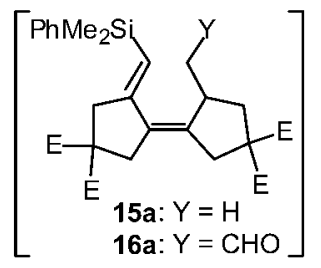

Although silyl group is not included in $\mathbf{1 4 a}$, no reaction takes place after $72 \mathrm{~h}$ in the absence of a hydrosilane, recovering the starting enediyne 13a. Thus, hydrosilane is proven necessary for this reaction to occur. A possible mechanism that can accommodate the formations of $\mathbf{1 4 , 1 5}$, and $\mathbf{1 6}$ is shown in Scheme 4 [10].

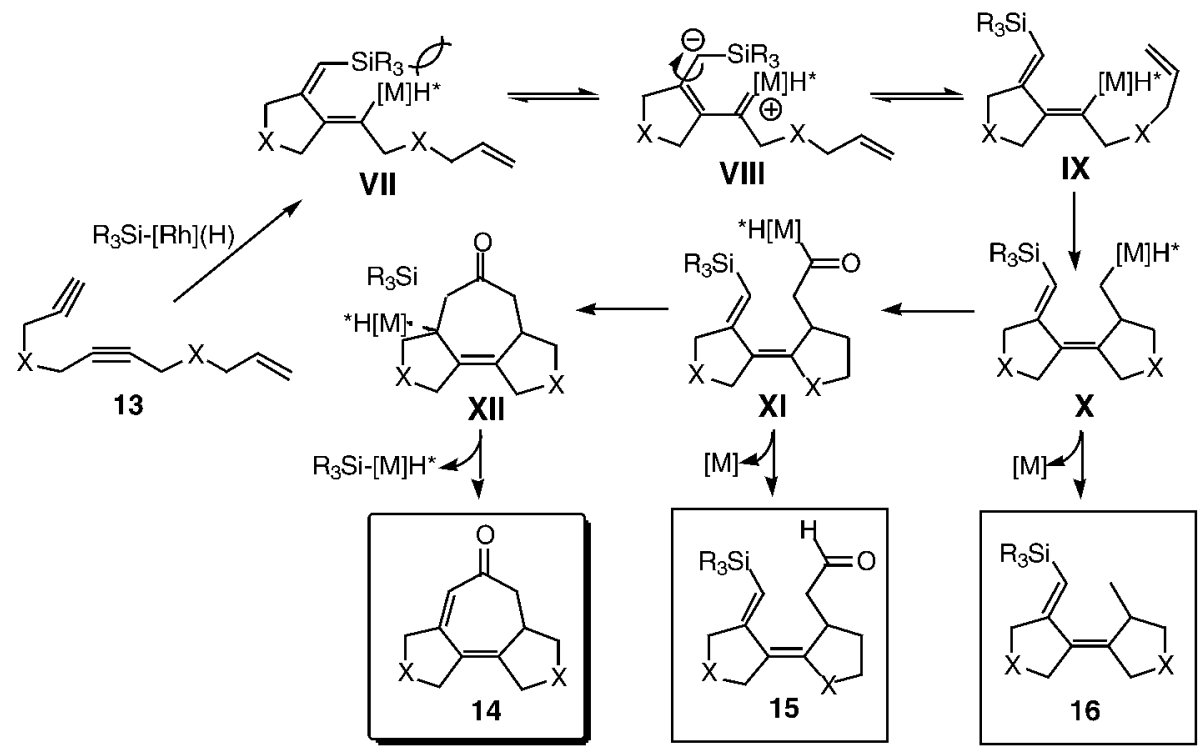

Scheme 4 
It is clear from this mechanism that only a catalytic amount of a hydrosilane should be necessary for the formation of $\mathbf{1 4}$ since the catalytically active $\mathrm{Si}$-[Rh] species should be regenerated from intermediate XII [10]. In fact, the use of a catalytic amount of $\mathrm{PhMe}_{2} \mathrm{SiH}$ brought about the exclusive formation of $\mathbf{1 4}$ by totally shutting out the formations of $\mathbf{1 5}$ and $\mathbf{1 6}$. Under the optimized conditions, i.e., the use of 0.5 equiv of $\mathrm{PhMe}_{2} \mathrm{SiH}$ at high dilution $(0.015 \mathrm{M})$ in THF, 14a was obtained in $92 \%$ isolated yield as the sole product (Scheme 3). Various functional groups, e.g., ether, ester, hydroxyl, and sulfonamide, and heteroatoms in the backbone of enediynes $\mathbf{1 4}$ are well tolerated in this reaction to give the corresponding fused 5-7-5 tricyclic products 15 in good to excellent isolated yields [10]. Other rhodium catalysts, $\mathrm{Rh}(\mathrm{acac})(\mathrm{CO})_{2}, \mathrm{Rh}_{4}(\mathrm{CO})_{12}$, and $\left[\mathrm{Rh}(\mathrm{CO})_{2} \mathrm{Cl}\right]_{2}$, show similar efficacy. As hydrosilane, $\mathrm{PhMe}_{2} \mathrm{SiH}$ is the best, but $\mathrm{Ph}_{2} \mathrm{MeSiH},(\mathrm{EtO})_{3} \mathrm{SiH}$, and $\mathrm{Et}_{3} \mathrm{SiH}$ can also be used.

\section{DESYMMETRIZATION OF HYDROSILOXYALKADIYNES BY INTRAMOLECULAR SILYLFORMYLATION}

Silylformylation of 1-alkynes has been extensively studied, which gives (Z)-1-silyl-2-formyl-1-alkenes with complete regio- and stereoselectivity [11]. The reaction of internal alkynes, however, is not regioselective. Accordingly, the intramolecular directed silylformylation has been developed to obtain the products with opposite regiochemistry as well as to achieve complete regio-control. For example, the reactions of $\omega$-dimethylsiloxyalkynes $\mathbf{1 7}$ and $\mathbf{1 9}$ catalyzed by $\mathrm{Rh}$ and $\mathrm{Rh}-\mathrm{Co}$ complexes proceed via exo-dig cyclization to give the corresponding 5-exo-formylalkylideneoxasilacycloalkanes $\mathbf{1 8}$ and $\mathbf{2 0}$, respectively, in excellent yields (Scheme 5) [12]. This reaction is applicable to $\omega$-disilylaminoalkynes, which gives aza-1-silacyclopentanes, e.g., $21 \rightarrow \mathbf{2 2}$ [13].

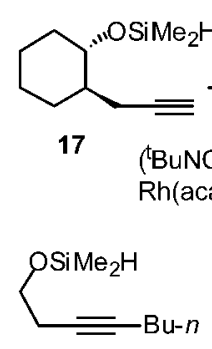

19

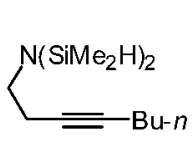

21

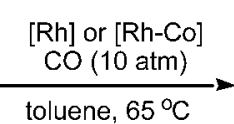

$14 \mathrm{~h}$ $14 \mathrm{~h}$

$\left({ }^{\mathrm{t}} \mathrm{BuNC}\right)_{4} \mathrm{RhCo}(\mathrm{CO})_{4}$ $\frac{\mathrm{Co}(10 \mathrm{~atm})}{\text { toluene, } 60^{\circ} \mathrm{C}, 14 \mathrm{~h}}$ $99 \%$

$\left({ }^{\mathrm{B}} \mathrm{BuNC}\right)_{4} \mathrm{RhCO}(\mathrm{CO})_{4}$

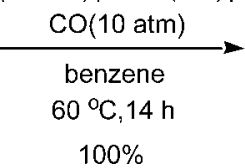

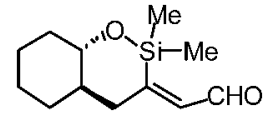

18

$96 \%$

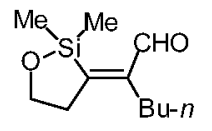

20

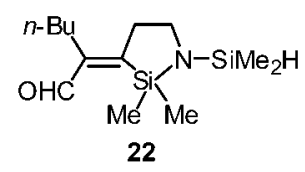

Scheme 5

Intramolecular silylformylation has successfully been applied to the desymmetrization of dimethylsilyloxyalkadiynes $\mathbf{2 3}$ catalyzed by $\mathrm{Rh}(\mathrm{acac})(\mathrm{CO})_{2}$, which affords 5-exo-(formylmethylene)oxasilacyclopentanes 24 in high yields (Scheme 6) [14]. Novel sequential double silylformylation of 23a also affords desymmetrization products 3-(3-silyl-2-formylprop-2-enyl)-5-exo(formylmethylene)oxasilacyclopentanes $\mathbf{2 5}$ in excellent yields. It has been shown that the intramolecular silylformylation is much faster than the intermolecular reaction so that 24a is formed exclusively in the beginning, followed by the second and intermolecular reaction to give $\mathbf{2 5}$ cleanly just by mixing all reactants at once (Scheme 6) [14]. These products are useful intermediates for the syntheses of polyhydroxy compounds of biological interest. 

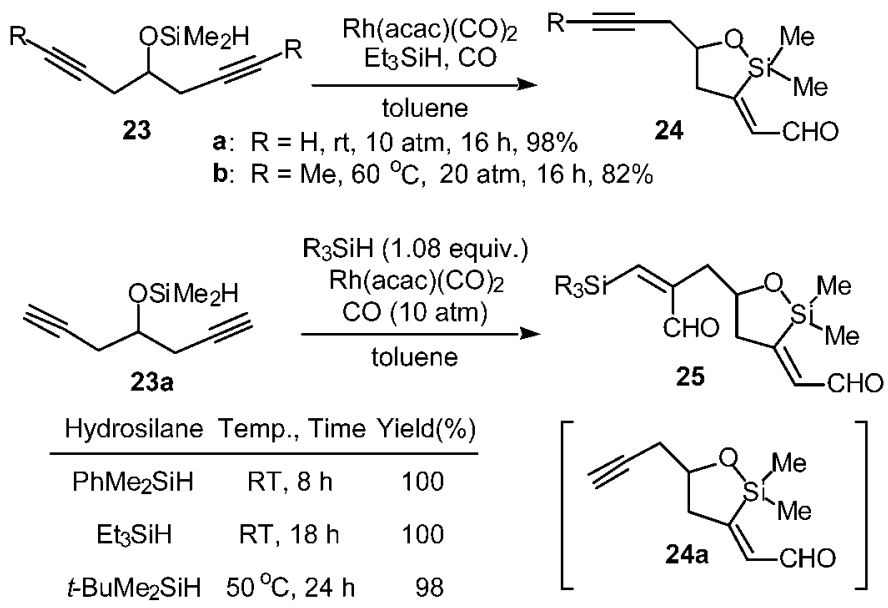

Scheme 6

\section{TOTAL SYNTHESIS OF ENANTIOPURE (+)-PROSOPININE USING CYCLOHYDROCARBONYLATION IN THE KEY STEP}

Cyclohydrocarbonylation reaction of alkenamides, alkenamines, or alkenols catalyzed by transition metals proceeds via hydroformylation followed by condensation of the resulting aldehyde with amide, amine, or alcohol moiety. This reaction provides efficient routes to various nitrogen and oxygen heterocycles.

This reaction has been successfully applied to the syntheses of (+)-prosopinine and (-)-deoxoprosophylline, which provide the shortest routes to these alkaloids in enantiopure form so far reported to date [15]. These piperidine alkaloids exhibit antibiotic and anesthetic properties. The short total synthesis of $(+)$-prosopinine is shown in Scheme 7 [15].
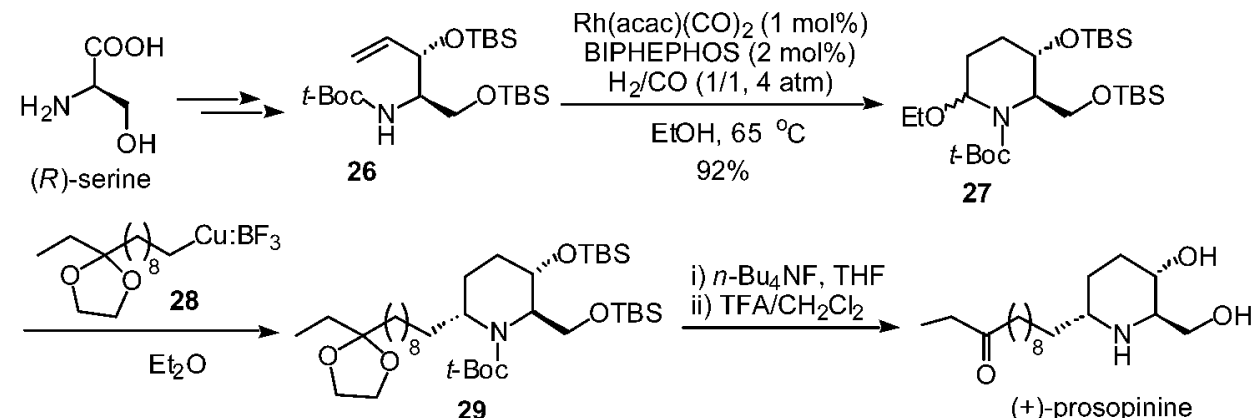

\section{Scheme 7}

The synthesis of (+)-prosopinine began with the elaboration of $(R)$-serine, to a $N$ - $t$-Boc-homoallylamine 26, which was subjected to cyclohydrocarbonylation catalyzed by $\mathrm{Rh}(\mathrm{acac})(\mathrm{CO})_{2}$-BIPHEPHOS complex to give the key intermediate 5,6-trans-2-ethoxypiperidine 27 in $92 \%$ yield. Ethoxypiperidine 27 was converted to (+)-prosopinine through the nucleophilic displacement of the ethoxy group with organocopper reagent $\mathbf{2 8}$, followed by deprotections via $\mathbf{2 9}$. 


\section{ENANTIOSELECTIVE DESYMMETRIZATION OF AMINODIENES}

Enantioselective cyclohydrocarbonylation has recently been applied to the efficient desymmetrization of 4-amido-1,6-dienes. For example, the reaction of 4-t-Boc-amino-1,7-diphenyl-1,6-heptadiene (30) catalyzed by $\mathrm{Rh}(\mathrm{acac})(\mathrm{CO})_{2}-(R, S)$-BINAPHOS) in toluene at $60{ }^{\circ} \mathrm{C}$ and $30 \mathrm{~atm}$ of $\mathrm{CO}$ and $\mathrm{H}_{2}(1: 1)$ gave 1- $t$-Boc-5,6-didehydropiperidine $\mathbf{3 1}$ with $93 \%$ ee and $98 \%$ de in $90 \%$ yield (eq. 5).[16] This type of enantio- and diastereoselective desymmetrization will find many applications in organic syntheses. Further studies on the scope of this reaction is actively underway in these laboratories.

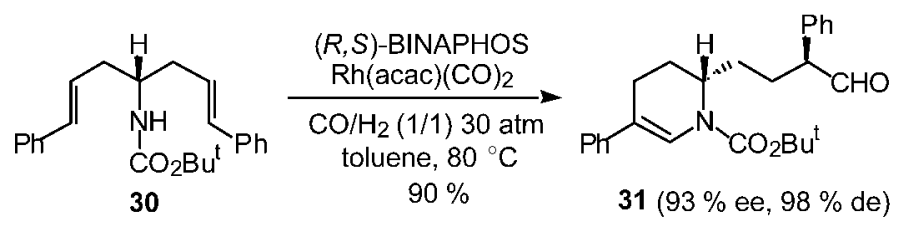

\section{NEW AND EFFICIENT ROUTES TO 1-AZABICYCLO[X.Y.0]ALKANE AMINO ACIDS}

Azabicyclo[x.y.0]alkane amino acids serve as conformationally restricted dipeptide surrogates, which are increasing their importance in the design of peptides and peptidomimetics for enzyme inhibitors and receptor antagonists or agonists. The cyclohydrocarbonylation has been successfully employed for the rapid syntheses of a variety of 1-azabicyclo[x.y.0] alkane amino acids directly from dipeptide substrates. Three examples are shown in Schemes 8 and 9 [17].<smiles>C=CC[C@H](NC(=O)[C@H](CO)NC(C)(C)C)C(C)=O</smiles>

32<smiles>C=CC[C@H](NC(=O)[C@H](CBr)NC(=O)O)C(=O)OC</smiles>

34

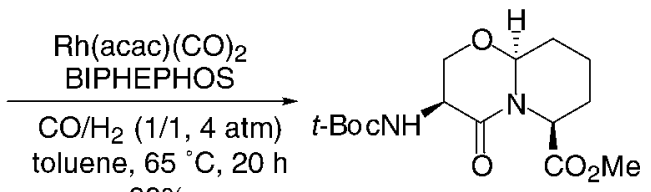

$93 \%$

Scheme 8

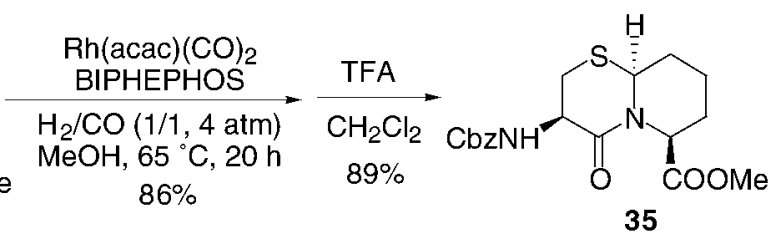<smiles>C=C[C@H](NC(=O)[C@H](CO)NC(C)(C)C)C(=O)OC</smiles>

Scheme 9 
Reaction of $(S, S)-N$ - $t$-boc-cysteylvinylglycinate $\mathbf{3 6}$ under the standard cyclohydrocarbonylation conditions gave the corresponding 5-oxa-1-azabicyclo[4.3.0]nonane amino acid ester 37. This reaction includes Rh-BIPHEPHOS catalyzed extremely linear selective hydroformylation to form aldehyde $\mathbf{3 8}$, followed by the formation of hemiamidal 39, subsequent generation of acyliminium ion $\mathbf{4 0}$, and the intramolecular nucleophilic addition of the hydroxyl group of the serine moiety to $\mathbf{4 0}$ to yield $\mathbf{3 7}$ (Scheme 9) [17].

\section{CONCLUSION}

Recent advances in the development of new cyclization reactions catalyzed by $\mathrm{Rh}$ complexes in these laboratories are summarized. These new reactions provide powerful methods for the rapid construction of a variety of skeletons relevant to biological active natural and unnatural substances. Cascade carbocyclizations will find many applications in the syntheses of fused carbocyclic and heterocyclic compounds and will be applicable to library syntheses.

\section{ACKNOWLEDGMENTS}

This research was supported by grants from the National Institutes of Health (NIGMS) and the National Science Foundation. Generous support from Mitsubishi Chemical Corp. is gratefully acknowledged.

\section{REFERENCES}

1. I. Ojima, R. J. Donovan, W. R. Shay. J. Am. Chem. Soc. 114, 6580 (1992).

2. I. Ojima, J. W. Zhu, E. S. Vidal, D. F. Kass. J. Am. Chem. Soc. 120, 6690 (1998).

3. S. Y. Lee. Ph.D. Thesis, State University of New York at Stony Brook (2000).

4. I. Ojima, M. Tzamarioudaki, C.-Y. Tsai. J. Am. Chem. Soc. 116, 3643 (1994).

5. I. Ojima, D. A. Fracchiolla, R. J. Donovan, P. Banerji. J. Org. Chem. 59, 7594 (1994).

6. I. Ojima, D. F. Kass, J.-W. Zhu. Organometallics 15, 5191 (1996).

7. I. Ojima, J. V. McCullagh, W. R. Shay. J. Organomet. Chem. 521, 421 (1996).

8. I. Ojima, A. T. Vu, J. V. McCullagh, A. Kinoshita. J. Am. Chem. Soc. 121, 3230 (1999).

9. (a) I. Ojima, N. Clos, R. L. Donovan, P. Ingallina. Organometallics 9, 3127 (1990); (b) R. S. Tanke and R. H. Crabtree. J. Am. Chem. Soc. 112, 7984 (1990).

10. I. Ojima and S. Y. Lee. J. Am. Chem. Soc. 122, 2385 (2000).

11. For a comprehensive review, see I. Ojima, C.-Y. Tsai, M. Tzamarioudaki, D. Bonafoux. In Organic Reactions, L. E. Overman (Ed.), Vol. 56, pp. 1-354, Wiley, New York (2000).

12. I. Ojima, E. S. Vidal, M. Tzamarioudaki, I. Matsuda. J. Am. Chem. Soc. 117, 6797 (1995).

13. I. Ojima and E. S. Vidal. Organometallics 18, 5103 (1999).

14. D. Bonafoux and I. Ojima. Org. Lett. 1303-1305 (2001).

15. I. Ojima and E. S. Vidal. J. Org. Chem. 63, 7999 (1998).

16. Z. Hua, N. Mizutani, P. Y. Zhang, I. Ojima. $221^{\text {st }}$ American Chemical Society National Meeting, Abstracts ORGN394 (2001).

17. N. Mizutani and I. Ojima. $221^{\text {st }}$ American Chemical Society National Meeting, Abstracts, ORGN395 (2001). 